\title{
К МЕТОДИКЕ ОПРЕДЕЛЕНИЯ ОТНОСИТЕЛЬНОГО ЗНАЧЕНИЯ ВИДОВ И ГРУПП МЛЕКОПИТАЮЩИХ В ОСТЕОЛОГИЧЕСКОМ МАТЕРИАЛЕ ИЗ РАСКОПОК АРХЕОЛОГИЧЕСКИХ ПАМЯТНИКОВ
}

\author{
К. Л. ПААВЕР, \\ кандидат биологических наук
}

\section{Введение. Значение количественного анализа костных материалов}

В настоящей статье автор, используя личный опыт определения костных остатков, добытых в последние годы при раскопках ряда археологических памятников Прибалтики,* дает сравнительный анализ некоторых показателей так называемой остеологической статистики. Имеются в виду некоторые спорные стороны методики оценки относительного значения видов (или групп видов) млекопитающих в остеологическом материале. При этом основное внимание уделяется оценке степени объективности и сравнимости цифровых данных, полученных тем или иным способом подсчета.

Следует указать, что интерес археологов и зоологов к изучению костных остатков, добываемых при археологических раскопках, за последнее время значительно возрос. Накапливающиеся остеологические материалы систематически разрабатываются в ряде научных учреждений нашей страны, а данные их обработки успешно используются палеозоологами, археологами и другими специалистами. Однако дальнейшее развитие этих исследований тормозится слабой разработанностью методики, необходимость уточнения которой неоднократно подчеркивалась в литературе. Разработки и унификации требует, в частности, и методика количественного анализа костного материала.

Развитие не только археологических, но и палеозоологических работ, как и само накопление больших количеств костных остатков, достигающих иногда (даже из раскопок одного памятника) десятков тысяч, заставляет исследователей искать пути для более полного использования этих богатых материалов, в первую очередь для более углубленной количественной характеристики палеофауны.

Основной целью количественного анализа остеологическото материала из археологических раскопок является оценка значения видов (или групп видов) животных в хозяйстве древнего населения. Получение таких данных тесно связано и с решением более узких палеозоологических вопросов, например с восстановлением состава и относительной численности видов в данной местности в период существования памятника. Однако в результате количественной обработки костных материалов, даже при применении наиболее совершенной мето-

* В 1955-1957 гг. автором определены костные остатки млекопитающих всего из 7 неолитических стоянок и 12 городищ и поселений Эстонии, Латвии и Литвы. Автор выражает благодарность всем археологам, предоставившим ему материалы для определения, 
дики сбора и подсчета, нельзя получить прямых и точных абсолютных данных о количестве использованных человеком животных. Для этого, даже при сравнительно небольшом количестве остатков, потребовалось бы провести огромную работу по выявлению половых, возрастных и индивидуальных различий для каждого из фрагментов многих костей, что вряд ли целесообразно.

Как известно, костные остатки, добываемые при раскопках какого-либо памятника, характеризуют не всю фауну позвоночных его окрестностей, а лишь промысловые (в более поздних памятниках и сельскохозяйственные) виды, при том в первую очередь более крупные (Н. К. Верещагин и И. М. Громов, 1953). Но даже кости этих видов в культурном слое памятника оказываются, как правило, в количестве, не соответствующем действительному числу убитых и использованных особей, что зависит как от тафономии памятника: места лова, доступности и техники добывания зверя и способа его хозяйственного использования (особенно в зависимости от того, является ли он мясным или пушным животным), - так и от того, в какой мере кости подвергались растаскиванию собаками и дикими хищниками. Имеют значение также и особенности самих костей: костные остатки разных видов, равно как и разные кости одного вида, сохраняются различным образом. Ввиду этого получаемые при статистической обработке остеологического материала цифровые данные недостаточно точно отражают истинные количественные соотношения видов и групा видов (особенно мелких, а также крупных непромысловых животных) в хозяйстве и природе прошлого.

Приблизительность цифровых данных «остеологической статистики» и необоснованность их механического применения без учета необходимых поправок подчеркивалась в последние годы как палеозоологами, так и археологами (В. И. Громова, 1948; Н. К. Верещагин, 1951; Е. И. Горюнова, 1950; Й. Бэсснек (J. Boessneck), 1956 и др.). Пользоваться этими данными, особенно в сравнительном плане, можно, лишь учитывая тафономию как данного типа захоронения вообще, так и частные тафономические особенности местонахождения (И. А. Ефремов, 1950). Разумеется, получаемые при этом выводы должны проверяться данными других наук, касающимися природных условий и хозяйственной деятельности населения в период образования культурного слоя.

\section{Об использовании показателя «количество остатков ”}

В настоящее время при невозможности определения истинного чиела особей пользуются двумя косвенными показателями: а) количество остатков (число определенных костей и костных фрагментов) и б) «минимальное количество особей», которым могли принадлежать подсчитанные остатки.

Еще недавно исследователи применяли преимущественно первый из них и значительно реже второй. В последнее время в работах, описывающих палеофауну археологических памятников, обычно приводятся параллельно данные по обоим показателям, однако встречаются также работы, в. которых относительных данных о количестве остатков уже вовсе не приводится и весь количественный анализ основывается на сравнении результатов подсчета «минимального количества особей».

Из отечественных авторов, описывавших палеофауну памятников материальной культуры и опубликовавших свои работы в последнее десятилетие, параллельные данные по подсчету количества остатков и минимальному количеству особей привели, например, В. И. Цалкин (1947), В. И. Громова (1948), К. С. Алексашина (1950) и др. Н. К. Верещагин и А. Д. Қолбутов (1957), рассматривая остатки животных из 
мустьерской стоянки под Сталинградом, приводят данные только о количестве остатков, указывая, что «минимальное количество особей» не было установлено ввиду раздробленности материала и его диффузного распределения по площади стоянки. В. О. Топачевский (1956) и О. Л. Короткевич (1956) не только приводят параллельно данные по обоим показателям, но вычисляют, кроме того, еще и суммарный живой вес особей всех установленных видов. В. И. Бибикова (1950) и А. Н. Формозов (1951) дают количественную оценку определяемых материалов на основании минимального количества особей.

Вопрос, каким из показателей - «количеством костей» или «количеством особей» - следует пользоваться при изучении костных остатков из археологических раскопок, более детально рассматривает В. И. Цалкин в своей интересной монографии, опубликованной в 1956 г. Этот автор приходит к выводу, что «для оценки значения того или иного вида в хозяйстве следует руководствоваться не количеством костей, а количеством особей» (стр. 124). В соответствии с этим он не приводит процентных данных о количестве остатков. А. Л. Монгайт в предисловии к упомянутой монографии, подчеркивая, что В. И. Цалкин уточнил методику статистического анализа остеологического материала из раскопок, пишет: «В основу его статистических расчетов кладется не количество костей, а количество особей, найденных при раскопках, - критерий, несомненно, более точный» (стр. 6). При слабой изученности вопроса, значительных различиях в подходе к его решению и трудностях установления «количества особей» такой вывод не представляется достаточно убедительвным.

С точки зрения оценки истинного значения вида (или группы видов) в остеологическом материале показатель «общее количество остатков» действительно несовершенен. Одним из главных, в литературе неоднократно отмеченных недостатков его является то, что он дает для видов с лучшей сорханностью костей завышенные цифры.

Цалкин (1956), рассматривая вопрос о применении относительных показателей для «остеологической статистики", подчеркивает зависимость результатов подсчета общего количества остатков от различий в массивности и прочности костей разных видов. Он отмечает далее, что различная прочность костей отдельных видов наглядно выражается в количестве остатков, приходящихся на одну особь. Он подчеркивает, что у видов с непрочными костями это количество меньше, главным образом ввиду того, что легче разрушимые и уничтожаемые элементы скелета (например у свиней кости конечностей) встречаются в меньшем числе.

Говоря о сохранности различных элементов скелета, В. И. Цалкин подчеркивает (не приводя, однако, фактического материала), что среди остатков крупного рогатого скота из раскопок Новгорода много костей конечностей, кости же черепа относительно немногочисленны. Наоборот, среди остатков свиней и мелкого рогатого скота попадается много различных костей черепа и сравнительно мало костей конечностей.

Мы пытались проанализировать частоту встречаемости различных элементов скелета домашних и диких животных с различной прочностью костей по Материалам из трех прибалтийских археологических памятников*. Из них стоянка Тамула (Эстонская ССР) является поздненеолитической, материал из городища Тервете (Латвийская ССР) относится к периоду от второй половины I тысячелетия н. э. до XIII века н. э. Куль-

* Материал из Тамула добыт Л. Янитсом, из Тервете - Э. Бривкалне, из Рыуге - М. Шмидехельм. 

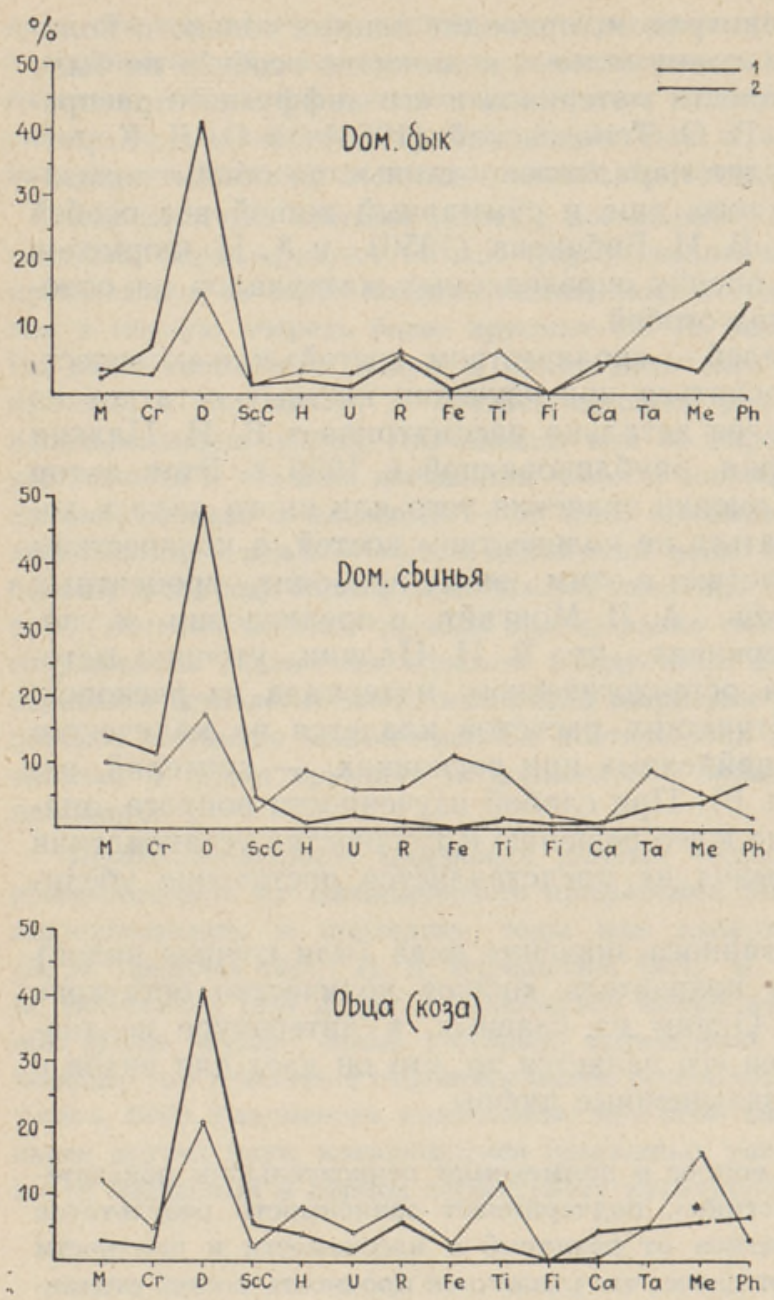

Рис. 1. Процентное соотношение остатков костей и костных фрагментов различных частей скелета домашних животных:

1 - из раскопок городища Тервете (4678 остатка).

2 - из раскопок городища Рыуге (551 остаток).

Обозначения: $M-$ нижн. челюсть, $\mathrm{Cr}$ - череп, $\mathrm{D}-$ зубы, $\mathrm{ScC}$ - кости поясов, $\mathrm{H}$ плечевая кость, $U$ - локтевая кость, $R$ - лучевая кость, $\mathrm{Fe}$ - бедренная кость, $\mathrm{T} i$ большая берцовая кость, $\mathrm{Fi}$ малая берцовая кость, $\mathrm{Ca}-$ кости запястья, Тa предплюсны, Ме - кости метаподий, $\mathrm{Ph}$ - фаланги.

турный слой городища Рыуге (Әстонская ССР) относится ко второй половине I тысячелетия н. э. Полученные результаты приведены в виде графиков на рис. 1 и 2. Подчеркиваем, что они иллюстрируют эту зависимость лишь в самых общих чертах. Для более точной характеристики сохранности отдельных элементов скелета необходимо учитывать одновременно и число одноименных костей (например фаланг, костей предплюсны, костей запястья, зубов и т. д.) в скелете. Процент остатков позвонков и ребер ввиду их немногочисленности на рисунках не указан.

Как видно из рис. 1, больших различий в сохранности одноименных костей у крупного рогатого скота, свиньи и мелкого рогатого скота не обнаруживается. У двух последних фаланги имеют несколько меньшее, а кости черепа несколько большее значение, чем у домашнего быка. Те же кости лося сохраняются, в общем, в таких же соотношениях, как и у крупного рогатого скота, лишь фаланг относительно больше (рис. 2). Сохранность элементов скелета бобра и куницы, как видов с менее прочными костями, иная. У них гораздо менее обычны кости запястья, пясти, предплюсны и плюсны, а также фаланги, несмотря на то, что количество этих костей в скелете у них больше, чем у копытных. В числе остатков бобра 

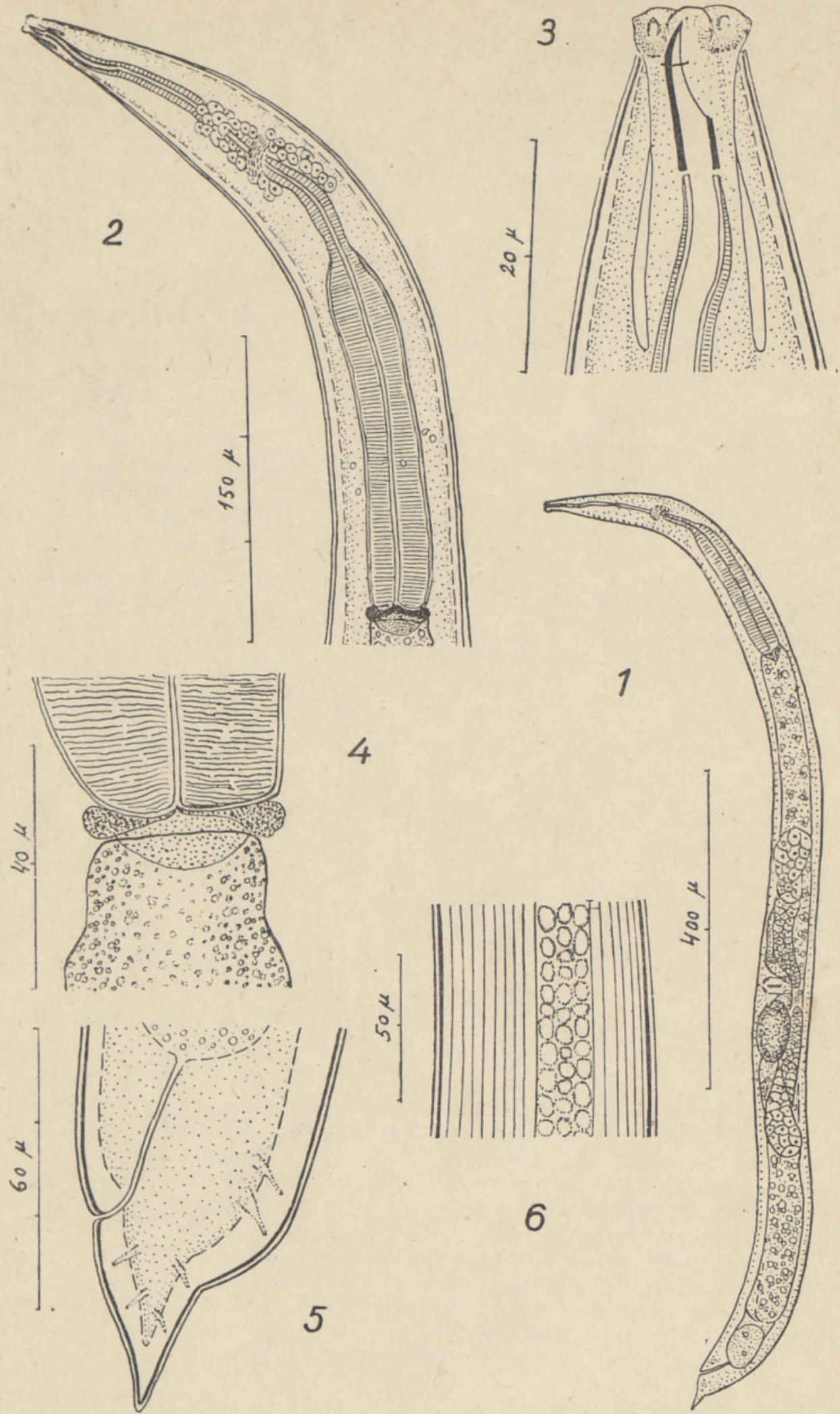

Рис. 1. Paraxonchium striatum gen. n. sp. n.

1 - общий вид, 2 - передняя часть тела, 3 - голова, 4 - задняя часть пищевода, 5 - хвост, 6 - боковое поле. 
c. 2. Процентное соотношен - остатков костей и костных фрагментов различных частей скелета охотничьих животных:

1 - из раскопок неолитической стоянки Тамула (3468 остатков);

2 - из раскопок городища Рыуге (769 остатков).

Обозначенйя частей скелета см. рис. 1 .
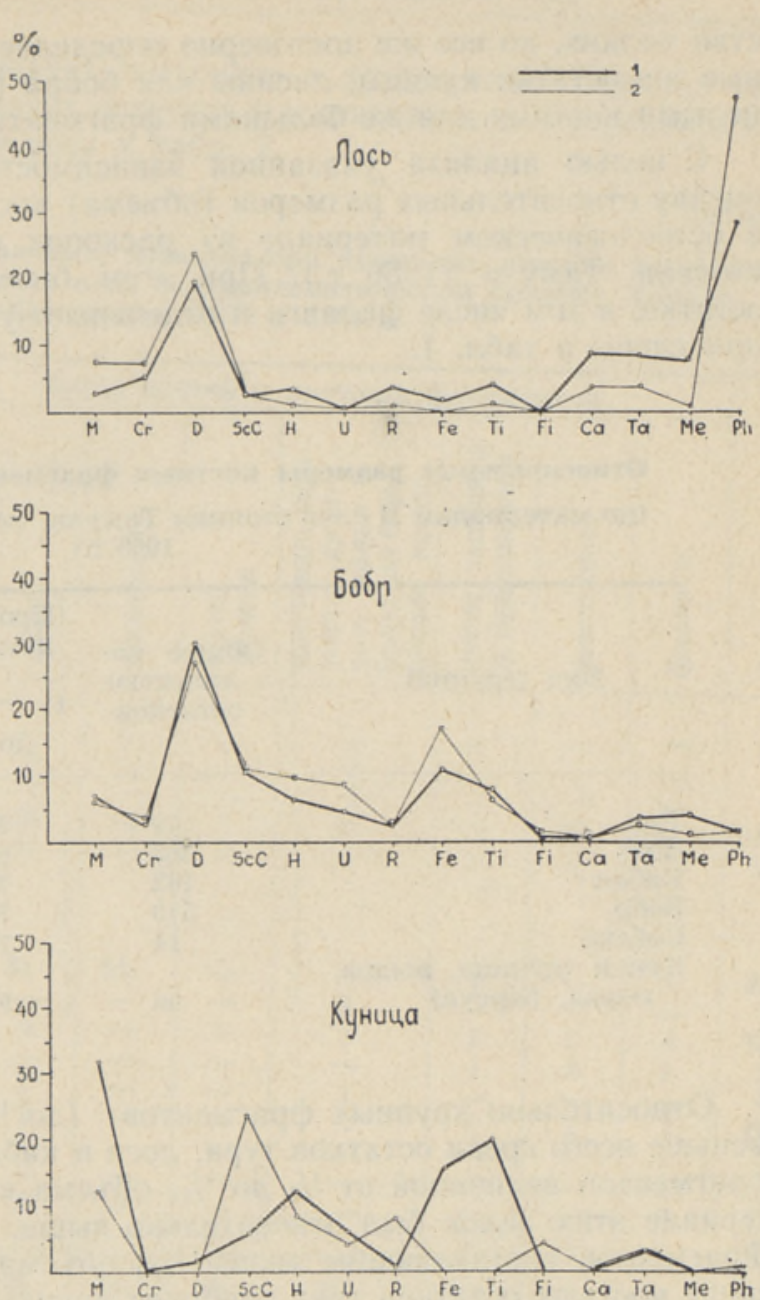

особенно многочисленны отдельные зубы*, а среди костей куницы преобладали нижние челюсти и почти не встречалось других костей черепа и отдельных зубов.

Различия в сохранности элементов скелета у отдельных видов не могут быть объяснены лишь различной прочностью и массивностью их костей. Несомненное влияние на состав сохранившихся остатков оказывают и другие тафономические факторы, в особенности характер использования туш убитых животных. В то же время надо подчеркнуть, что общее количество остатков, сохранившихся от одного скелета, зависит как от раздробленности костей, так и от их размеров. Ведь трубчатая кость очень крупного зверя, например мамонта, может дать, как указывают Н. К. Верешагин и А. Д. Колбутов (1957), больше осколков, чем такая же кость лошади или сайгака. От трубчатых костей лошади, домашнего быка или лося получается и сохраняется сравнительно большое количе-

\footnotetext{
* Бросается в глаза, что наибольшее количество отдельных зубов по всем видам встречается в материалах из Рыуге, где условия для сохранения костного вещества неблагоприятны (песчаная почва).
} 
ство мелких, но все же достоверно определяемых фрагментов. Одноименные же остатки куницы, лисицы или бобра представлены нередко почти целыми костями или же большими фрагментами.

С целью анализа указанной зависимости мы провели глазомерную оценку относительных размеров (объема) костных остатков разных видов в остеологическом материале из раскопок второго слоя неолитической стоянки Тамула (1956 г.). При этом были учтены все определенные остатки, в том числе фаланги и отдельные зубы. Полученные результаты приведены в табл. 1 .

Таблица 1

Относительные размеры костных фрагментов различных зверей

(по материалам II слоя стоянки Тамула, Эстонская ССР, раскопки 1956 г.)

\begin{tabular}{|c|c|c|c|c|}
\hline \multirow[t]{2}{*}{ Вид (группа) } & \multirow{2}{*}{$\begin{array}{l}\text { Общее ко- } \\
\text { личество } \\
\text { остатков }\end{array}$} & \multicolumn{3}{|c|}{$\begin{array}{l}\text { Процент определенных фраг } \\
\text { ментов, составляющих от це- } \\
\text { лой кости }\end{array}$} \\
\hline & & до $1 / 4$ & $\begin{array}{l}\text { от } 1 / 4 \\
\text { до } 1 / 20\end{array}$ & $\begin{array}{c}\text { менеe } \\
1 / 20 \\
\end{array}$ \\
\hline Typ & 79 & 59,4 & 32,9 & 7,6 \\
\hline Лось & 365 & 62,7 & 31,5 & 8,5 \\
\hline Кабан & 162 & 71,0 & 27,2 & 1,8 \\
\hline Бобр & 513 & 74,9 & 25,1 & - \\
\hline Собака & 14 & 78,6 & 21,4 & 一 \\
\hline $\begin{array}{l}\text { Куньи (куница, выдра, } \\
\text { норка, барсук) }\end{array}$ & 46 & 93,5 & 6,5 & - \\
\hline
\end{tabular}

Относительно крупных фрагментов (до $1 / 4$ объема кости) оказалось меньше всего среди остатков тура, лося и кабана. В то же время процент фрагментов величиной от $1 / 4$ до $1 / 20$ объема кости в остеологическом материале этих видов был относительно выше, чем у более мелких видов. Фрагменты, составляющие менее $1 / 20$ объема кости, встречались только среди костных остатков трех наиболее крупных видов. Почти все остатки куньих оказались фрагментами размером более $1 / 4$ от объема кости. Если взять для анализа фрагменты одних трубчатых костей, то описанная закономерность выражена еще резче.

Костные обломки крупных видов, составляющие даже лишь небольшую часть от данной кости, по своим абсолютным размерам зачастую все же крупнее и тяжелее, чем целые кости мелких видов. Это также способствует лучшему сохранению фрагментов и осколков костей крупных видов, поскольку тяжелые обломки, как и обломки, не содержащие костного мозга и остатков связок, реже растаскиваются пернатыми и четвероногими хищниками (Н. К. Верещагин и А. Д. Колбутов, 1957).

Известно, что влияние различий в размерах одноименных костей отдельных видов отражается на результатах подсчета еще и потому, что мелкие кости при раскопках часто остаются ненайденными (Й. Бэсснек, 1956). При раскопках стоянки Тамула в 1956 г., проведенных на достаточно высоком методическом уровне под руководством кандидата исторических наук Л. Янитса, автор провел сбор мелких остатков, не собранных при раскопках. С этой целью в больших ведрах с дном из металлической сетки (размер ячейки $2 \times 2$ мм) было промыто 2 м $^{3}$ уже просмотренного археологами и выброшенного в отвал сильно перемешанного с торфом грунта, содержащего культурный слой. На дне ведра осталось 
большое количество (тысячи) позвонков и других костей рыб, а также некоторое количество мелких остатков млекопитающих. Результаты определения последних приведены в табл. 2.

Таблица 2

Костные остатки млекопитаюцих, добытые при промывке отвалов разобранного археологами культурного слоя !поздненеолитической стоянки Тамула (Эстонская ССР) в 1956 r.

\begin{tabular}{|c|c|c|c|c|c|c|c|c|c|}
\hline \multirow[b]{2}{*}{ Вид д } & \multicolumn{8}{|c|}{ Число костей и костных фрагментов } & \multirow[b]{2}{*}{$\begin{array}{l}\text { 연 } \\
\text { ஹू } \\
\text { ๓ }\end{array}$} \\
\hline & 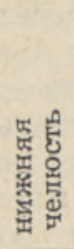 & స్లో & 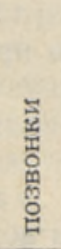 & 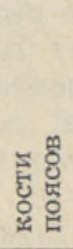 & 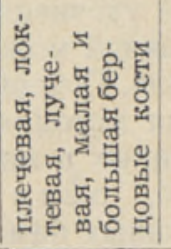 & 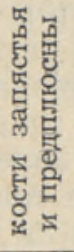 & 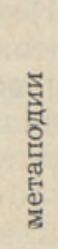 & 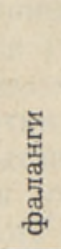 & \\
\hline Ёж & 1 & - & - & - & - & - & - & - & 1 \\
\hline $\begin{array}{l}\text { Бурозубка } \\
\text { Белка }\end{array}$ & - & 2 & - & - & 1 & - & $\bar{z}$ & - & 3 \\
\hline $\begin{array}{l}\text { Белка } \\
\text { Бобр }\end{array}$ & $\overline{2}$ & $\overline{16}$ & $\overline{14}$ & $\overline{1}$ & $\begin{array}{r}2 \\
17\end{array}$ & $\overline{6}$ & 13 & $\overline{39}$ & 108 \\
\hline $\begin{array}{l}\text { Водяная полевка } \\
\text { Другие мышевид- } \\
\text { ные грызуны, бли- } \\
\text { же не определен- }\end{array}$ & - & 17 & 一 & - & 1 & - & - & - & 18 \\
\hline $\begin{array}{l}\text { ные } \\
\text { Заяц }\end{array}$ & 6 & 31 & 53 & - & $\begin{array}{l}1 \\
1\end{array}$ & 1 & 二 & - & 92 \\
\hline $\begin{array}{l}\text { Заяц } \\
\text { Куница. }\end{array}$ & 13 & $\overline{5}$ & - & $\overline{1}$ & $\begin{array}{l}1 \\
1\end{array}$ & $\overline{2}$ & 8 & $\overline{4}$ & $\begin{array}{r}1 \\
34\end{array}$ \\
\hline Норка, (хорек?) & - & $\overline{3}$ & - & 一 & - & 1 & 3 & 1 & 5 \\
\hline $\begin{array}{l}\text { Барсук } \\
\text { Выдра }\end{array}$ & $\overline{2}$ & $\begin{array}{l}3 \\
2\end{array}$ & $\overline{-}$ & - & $\begin{array}{l}1 \\
1\end{array}$ & $\overline{1}$ & $\overline{2}$ & $\overline{3}$ & 4 \\
\hline Кабан & - & 1 & - & 一 & - & - & 1 & 2 & 4 \\
\hline Благородный олень & - & - & - & - & - & - & - & 1. & 1 \\
\hline $\begin{array}{l}\text { Лось } \\
\text { Косуля }\end{array}$ & - & $\stackrel{3}{-}$ & 二 & $\overline{-}$ & - & - & $\underline{-}$ & $\begin{array}{l}3 \\
1\end{array}$ & $\begin{array}{l}6 \\
1\end{array}$ \\
\hline Итого & 24 & 80 & 67 & 2 & 26 & 11 & 27 & 54 & 291 \\
\hline
\end{tabular}

Приведенные данные показывают, что даже при хорошей сохранности костного материала, несмотря на тщательность работы археологов, известное количество остатков (в первую очередь мелких костей скелета) мелких и средних видов: куниц, бобра, выдры, мелких грызунов и других - остается все же не обнаруженным. Дополнительный сбор остатков, проведенный нами, не охватил и 200-ой части всего объема исследованного культурного слоя. При полном же дополнительном рассмотрении последнего найденное количество остатков мелких млекопитающих достигло бы нескольких тысяч и относительное значение видов сильно изменилось бы по сравнению с известным до сих пор. Кардинально изменилось бы и количественное соотношение остатков рыб и млекопитающих.

Известное влияние, искажающее действительное значение вида в костном материале, может оказать и неполнота определения материала. Должны быть учтены и различия, обусловленные трудностями определения одноименных костей у близких видов. Так, даже мелкие фрагменты костей бобра хорошо определимы, различить же некоторые остатки кабана и домашней свиньи или же домашнего быка и мелкого тура или зубра при большой раздробленности материала иногда весьма трудно или даже невозможно. Вследствие этого уменьшается значение этих видов в сводных данных по подсчету количества остатков.

В отношении видов, кости которых обладают в известных пределах одинаковой прочностью и размерами, подсчет общего количества остатков дает, при прочих равных условиях, довольно хорошо сравнимые данные. 


\section{«Количество особей» как показатель «остеологической статистики»}

При критическом рассмотрении показателя «м ин и м льное кол и ч е с т в о о с б ей» сразу бросается в глаза несовершенство применяемой в настоящее время методики его определения. Обычно оно сводится просто к подсчету количества правых и левых экземпляров какойлибо одной парной кости (см. В. И. Цалкин, 1956, стр. 120), что не позволяет учитывать ни возрастных, половых и индивидуальных различий остатков, ни разновременности их захоронения в пределах данного местонахождения. Некоторое уточнение результатов подсчета путем более подробного изучения различий может быть проведено лишь при относительно небольшом материале. Совершенно очевидно, что при разработке массового материала такая методика позволяет выявить лишь не котор у ю часть представленных в материале особей, притом н е и з в е с т н о какую и, кроме того, разную у различных видов.

При этом для отдельных памятников возможны большие несоответствия, зависящие от особенностей формирования их культурного слоя, характера захоронения остеологического материала, условий сохранности остатков и их распределения по площади местонахождения. Так, костный материал, подсчитываемый для одного культурно-исторического комплекса, нередко подвергался захоронению в течение длительного периода (иногда многих столетий) и был собран со значительной площади. В подобном случае вполне возможно даже такое положение, при котором каждый второй-третий найденный фрагмент принадлежит отдельной особи. Понятно, что учет количества особей по одной или даже нескольким парным костям дает в этом случае совершенно искаженные результаты и истинное число использованных особей намного превышает устанавливаемую подсчетом цифру. Сильная зависимость от о бще го количества материала является весьма о трицательным ка чест вом «минимального количества особей»как к о л и ч с т в е н н г о показателя. Этот существенный недостаток уже отметила В. И. Громова (1948). Она указала, что «минимальное количество особей» соответствует истинному лишь при числе остатков менее $30-50$, при большем же количестве остатков разница будет значительной. Число неподсчитанных особей оказывается большим при обширном материале, следовательно, подсчет минимального количества особей дает наиболее искаженные результаты именно при материале, представляющем наибольший интерес и имеющем наибольшее значение. Это же обстоятельство отметил Э. Кун (Е. Kuhn, 1938) (цит. по И. Бэсснек, 1956), указавший, что при увеличении разрабатываемого костного материала «минимальное количество особей» отстает от количества остатков.

Для исследования указанной особенности автор предпринял попытку проанализировать ее на корреляционных диаграммах (рис. 3). На рисунке точками изображено число остатков, приходящихся на «одну особь»* у некоторых наиболее обычных видов субфоссильной фауны археологических памятников Прибалтики при различном количестве остатков, не превышающем, однако, двухсот. Материал, послуживший основой для приведенных графиков, добыт на неолитической стоянке Тамула (костные остатки лося и бобра) и в городище Тервете (костные остатки домашнего быка и домашней свиньи). Следует особо подчеркнуть, что весь материал по каждому виду в отдельности добыт из слоев с одинаковыми условиями захоронения и сохранности.

* Число «особей» получено обычной методикой подсчета «минимального количества особей» и является, следовательно, неточным. Отсюда вытекает условность выражения «одна особь», 

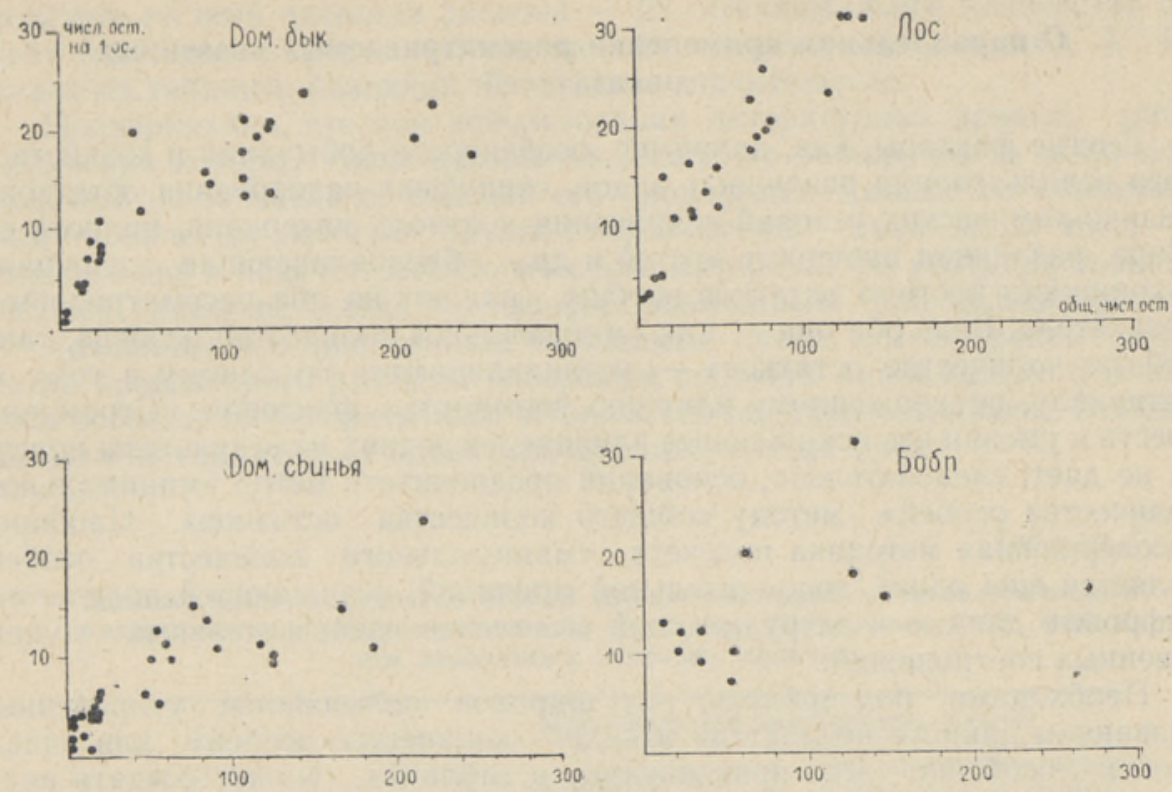

Рис. 3. Число остатков, пгиходяшихся на одну особь при различном количестве учтенного материала. По оси абсцисс отмечено количество остатков, по оси ординат - число остатков, приходящихся на одну особь.

Непостоянство числа остатков, приходящихся на одну «особь» при различном количестве материала, очевидно. У домашнего быка, домашней свиньи и лося это число с увеличением общего количества материала быстро растет, но не одинаково у каждого из них. Данные по остаткам бобра не позволяют вполне точно установить характер этой зависимости, возможно, отчасти из-за небольшого числа отдельных точек. Можно думать, что намечающиеся различия в какой-то степени отражают специфичные черты остеологического материала отдельных видов и памятников. В таком случае подобные диаграммы в дальнейшем могли бы быть использованы для исследования и характеристики костного материала.

Число остатков, приходящихся на одну «особь», вычисляется на основе данных подсчета костных остатков по обоим показателям. Значительная изменчивость этого числа, следовательно, не может быть использована для доказательства непригодности только метода «общего количества» остатков. Эта изменчивость скорее выражает несовершенство обоих рассматриваемых показателей.

На зависимость «минимального количества особей» от количества учтенных остатков вполне обоснованно указывает и В. И. Цалкин. Он утверждает (1956, стр. 122), что «чем больше костей того или иного вида, тем дальше отступает от действительности результат подсчета особей». Но из этого подчеркнутого им обстоятельства он, к сожалению, не делает соответствующего вывода о неточности и малой пригодности «минимального количества особей» как показателя при разработке массового материала.

Следует учесть, что ввиду большой раздробленности «кухонных остатков» подсчет приходится вести не по цёлым костям, а по их обломкам, что очень затрудняет определение числа особей, в особенности бопато представленных видов. При большой раздробленности материала результаты подсчета «минимального количества особей» наиболее условны. 


\section{O параллельном применении рассматриваемых косвенных показателей}

Другие факторы, как, например, особенности добывания и хозяйственного использования различных видов, специфика захоронения остатков и физико-химических условий сохранения костного материала, полнота его сбора, различная прочность костей и др., обусловливающие различия в сохранности костных остатков вообще, влияют на оба рассматриваемых показателя. Ведь оба они - как «минимальное количество особей», так и «общее количество остатков» - устанавливаются по одному и тому же материалу, подверженному влиянию упомянутых факторов. Стремление учесть и уменьшить искажающее влияние последних на результаты подсчета не дает, следовательно, оснований предпочитать метод «минимального количества особей» методу «общего количества остатков». Наоборот, несовершенная методика подсчета «минимального количества особей» является еще одной дополнительной причиной, искажающей получаемые цифровые данные и затрудняющей выявление действительных количественных соотношений.

Необходимо подчеркнуть, что широкое пользование укороченным названием данного показателя в виде «количество особей» или «число особей», особенно часто практикуемое в таблицах, может создать видимость, что мы имеем дело с чем-то определенным, точным, абсолютным, а не с относительными и условными цифрами, и поэтому является нежелательным. Само название «минимальное количество особей» также условно. Поскольку выражаемое им число в действительности является весьма условным, вернее было бы назвать его «условным числом особей».

Возникает вопрос, целесообразно ли вообще пользоваться «общим количеством остатков» и «минимальным количеством особей»? Несмотря на все недостатки рассматриваемых показателей, ответ на этот вопрос должен быть положительным. На современном этапе разработки методов количественной оценки остеологического материала эти показатели все же дают полезную и незаменимую информацию по ряду вопросов, о чем свидетельствуют хотя бы интересные данные, опубликованные в работах последнего времени. В свете приведенных выше данных и высказанных соображений нельзя считать достаточно обоснованным также и отказ от использования показателя «общего количества остатков», ибо «минимальные количества особей» не являются по сравнению с ним более точным и объективным.

Один из решающих моментов при сравнительной оценке пригодности рассматриваемых показателей связан с необходимостью сравнения количественных данных не только по отдельным видам или группам, о чем в основном шла речь выше, но и по разным слоям, раскоп а и п а м я т и к а м. С этой точки зрения «минимальное количество особей» является, безусловно, менее подходящим показателем, чем «общее количество остатков». Последнее не изменяется в зависимости от того, определяется ли остеологический материал в одном комплексе по всему памятнику или же по отдельным слоям, квадратам, раскопам и ярусам с последующим суммированием полученных данных. «Минимальное количество особей», наоборот, зависит от этого в весьма значительной степени.

Это довольно понятное обстоятельство может быть проиллюстрировано следующим конкретным примером. При раскопках городища Лыхавере (Әстонская ССР; начало XIII в.; раскопки Х. Моора) в 1956 г. было собрано всего 2030 костей, костных фрагментов и мелких осколков. Из них определимых остатков млекопитающих было 311. При подсчете по отдельным квадратам жминимальное количество особей» равнялось 129 , при 
подсчете по всей площади раскопа - 27. «Минимальное количество особей» отдельных видов по обоим способам подсчета дано в табл. 3 . Қак видно из таблицы, различия получились значительные.

Подчеркиваем, что для использования литературных данных, способ получения которых часто неизвестен, особенно важно, чтобы результаты подсчета не зависели от способа его проведения. Данные по «минимальному количеству особей» труднее используемы также ввиду того, что определение и подсчет остеологического материала по унифицированному способу далеко не всегда оказывается возможным или целесообразным.

Различные оредние данные, выводимые путем суммирования результатов проведенного разными способами подсчета «минимального количества особей», не показательны. В таком случае даже массовость исходных данных не гарантирует объективности полученных цифр.

Таб̆лица 3

Минимальное количество особей млекопитающих в остеологическом материале из раскопок городища Лыхавере (Эстонская ССР, 1956 г.) при различных способах подсчета

\begin{tabular}{|c|c|c|c|c|}
\hline \multirow{3}{*}{ В и д } & \multicolumn{4}{|c|}{ Минималыное количество особей } \\
\hline & \multicolumn{2}{|c|}{$\begin{array}{c}\text { при подсчете по } \\
\text { квадратам }\end{array}$} & \multicolumn{2}{|c|}{$\begin{array}{c}\text { при подсчете всего } \\
\text { материала в одном } \\
\text { комплексе }\end{array}$} \\
\hline & число & $\%$ & число & $\%$ \\
\hline Заяц & 4 & 3,1 & 1 & 3,4 \\
\hline Мелкий грызун & 1 & 0,7 & 1 & 3,4 \\
\hline Водяная полевка & 5 & 3,9 & 4 & 13,8 \\
\hline Собака & 7 & 5,4 & 2 & 6,9 \\
\hline Тюлень & 1 & 0,7 & 1 & 3,4 \\
\hline Лошадь & 3 & 2,3 & 2 & 6,9 \\
\hline Кабан & 2 & 1,5 & 1 & 3,4 \\
\hline Домашняя свинья & 48 & 37,2 & 6 & 20,7 \\
\hline Лось & 3 & 2,3 & 1 & 3,4 \\
\hline Косуля & 3 & 2,3 & 3 & 10,3 \\
\hline Домашний бык & 17 & 13,4 & 3 & 10,3 \\
\hline Овца (или коза) & 35 & 27,1 & 4 & 13,8 \\
\hline И того & 129 & 100 & 29 & 100 \\
\hline
\end{tabular}

Следует учесть, что определение удельного значения видов сельскохозяйственных или охотничьих животных в питании древнего населения по количеству мяса, полученному от использованных особей, или же по их живому весу также дает лишь условные результаты. В настоящее время еще недостаточно разработаны средние показатели выхода мяса от одного или другого вида, а, главное, количество иопользованных в пищу особей не может быть достаточно точно установлено. Однако как дополнительный условный показатель общий живой вес иопользованных особей вполне может быть использован.

При статистическом анализе остеологического материала следует пользоваться тем или иным количественным показателем в зависимости от характера материала и задач его исследования. Желательно по возможности приводить параллельные данные, полученные обоими способами. Әто позволяет полнее и точнее охарактеризовать определяемый костный материал и ввести взаимные коррективы. Необходимость последних подчеркнута В. И. Громовой (1948), указавшей, что истинное процентное соотношение числа представленных в материале животных будет состав- 
лять нечто среднее между цифрами, полученными в результате подсчета количества остатков и подсчета минимального количества особей.

Для обеспечения возможно более широкого сравнения материалов различных памятников, слоев и раскопов данные о количестве остатков должны приводиться в первую очередь.

\section{Краткие выводы}

1. Вычисляемые при количественной разработке остеологического материала статистические показатели требуют критического подхода при их использовании и могут быть применены для характеристики палеофауны и ее значения лишь при одновременной всесторонней оценке тафономической специфики материала.

2. Первоочередной задачей количественного анализа костных остатков является оценка удельного значения видов и групп животных в данном материале. Это может быть наиболее точно выражено истинным (абсолютным) числом особей, к которым относятся определенные остатки вида или группы видов. Однако при массовом материале истинное число представленных в нем особей практически не может быть установлено.

3. Вместо этого в настоящее время в качестве относителіных показателей применяют «общее количество остатков» и «минимальное количество особей», которые оба отражают реальные количественные соотношения неточно. Пользование только одним из них, например «минимальным количеством особей», не содействует полной и объективной характеристике материала.

4. Данные по подсчету «общего количества остатков» из различных памятников и слоев являются более сравнимыми. «Минимальным количеством особей» целесообразно пользоваться как параллельным показателем, в первую очередь при анализе палеофауны памятников и слоев, костный материал которых накопился в сравнительно короткое время и не является слишком раздробленным или диффузно распределенным.

5. Название «минимальное количество особей» является условным. Учитывая, что этот показатель охватывает не определенно минимальную, а в зависимости от различных обстоятельств весьма различную часть особей, желательно назвать его «условным числом особей».

6. Необходимо дальше развивать методику сбора и обработки остеологического материала, в том числе из памятников материальной культуры, изучая причины, обусловливающие выборочность его накопления и захоронения и уточняя возможности применения статистических и графических приемов.

\section{ЛИТЕРАТУРА}

А л ексашин а К. С., 1950. Остатки фауны из некоторых городищ Верхнего Поволжья. Матер. и исслед. по археол. СССР, № 13.

Бибико в а В. И., 1950. Фауна Пекуновского городища. Матер. и исслед. по археол. СССР, № 13.

Ве рещагин Н. К., 1951. Хищные (Carnivora) из бинагадинского асфальта. Тр. Естеств.-истор. музея АН Аз. СCP, VI.

В е р ещ аг ин Н. К. и Г ром о В И. М., 1953. Сбор остатков высших позвоночных четвертичного периода. В пом. работ. на полезащ. лесн. пол. и на вел. стр. ком., № 20.

Верещ агин Н. К. и Колбутов А. Д., 1957. Остатки животных на мустерской стоянке под Сталинградом и стратиграфическое положение палеолитического слоя. Тр. Зоол. ин-та АН ССР, т. XXII.

Гром о ва В. И., 1948. Остатки млекопитающих из раннеславянских городищ вблизи г. Воронежа. Матер. и иссл. по археол. СССР, № 8.

Горюнова Е. И., 1950. К вопросу об «остеологической статистике». КСИиМк, вып. XXXV. 
Е фре м в И. А., 1950. Тафономия и геологическая летопись. Тр. Палеонтол. ин-та, XXIII, выпr. 1.

Короткевич О. Л., 1956. Фауна позднетрипольского поселения Сандраки. Збірник праць Зоол. музею АН УССР, № 27.

Т о п чев ски й В. О., 1956. Фауна Ольвии. Збірник праць Зоол. музею АН УCCP, № 27.

Форм о ов А. Н., 1951. Материалы к истории фауны Приветлужья. Матер. иссл. по арх. СССР, № 22.

Ц а л к и н В. И., 1947. Палеофауна старой Рязани. КСИимК, вып. ХХІ.

Ц а л к и н В. И., 1956. Материалы для истории скотоводства и охоты в древней Руси по данным изучения костных остатков из раскопок археологических памятников лесной полосы Европейской части СССР. Матер. и иссл. по археол. СССР, № 51.

Boesseneck, J., 1956. Tierknochen aus spätneolitischen Siedlungen Bayerns. Studien an vor- und frühgeschichtlichen Tierresten Bayerns. München.

Kuhn, E., 1938. Zur quantitativen Analyse der Haustierwelt der Pfahlbauten in der Schweiz. Vierteljahrsschr. Nat.-forsch. Ges. 83. Zürich.

\title{
IMETAJATE LIIKIDE JA RÜHMADE SUHTELISE OSATÄHTSUSE MÄARAMISE METOODIKAST ARHEOLOOGILISTE MÄLESTUSMÄRKIDE LUUMATERJALIS
}

\author{
K. Paaver, \\ bioloogiateaduste kandidaat
}

\section{Resümee}

Arheoloogilistel kaevamistel hulgaliselt kogutavad loomade kivistunud ja poolkivistunud luujäänused on väärtuslikuks teaduslikuks materjaliks, mille läbitöötamise tulemustel on oluline tähtsus paleozooloogias, arheoloogias jt. teadusharudes. Selle materjali alusel tehtavate järelduste ulatuslikuma kasutamise seisukohalt on muu hulgas oluline tema kogumise ja statistilise läbitöötamise metoodika edasine arendamine, Kasutades Baltimaade arheoloogiliste mälestusmärkide luumaterjali määramise andmeid ja kogemusi, käsitleb autor käesolevas artiklis mõningaid nn. "osteoloogilise statistika» vaieldavaid küsimusi, eriti seoses paleofauna analüüsiga.

Osteoloogilise materjali statistilisel läbitöötamisel saadavatesse näitajatesse tuleb suhtuda kriitiliselt. Neid vőib kasutada paleofauna iseloomustamiseks vaid antud luumaterjali tafonoomilist spetsiifikat igakülgselt arvestades.

Osteoloogilise materjali kvantitatiivse analüüsi esmaseks ülesandeks on eri loomaliikide ja loomarühmade suhtelise osatähtsuse kindlakstegemine antud materjalis. Seda väljendab kőige täpsemini isendite tõeline (absoluutne) arv, kellelt määratud luud ja luufragmendid pärinevad. Massilise materjali korral ei ole tõeline luude arv real põhjustel praktiliselt määratav ning selle asemel kasutatakse suhtelisi näitajaid «luude üldarvu» ja «isendite minimaalset arvu». Mõlemad need näitajad väljendavad aga liikide või rühmade osatähtsust antud materjalis ebatäpselt. Ainult ühe näitaja, nimelt «isendite minimaalse arvu» kasutamine ei tõsta analüüsi tulemuste täpsust.

Eri mälestusmärkide ja eri kihtide fauna on paremini võrreldav «luude üldarvu» alusel. "Isendite minimaalset arvu» on otstarbekohane kasutada paralleelse näitajana, eriti nende kihtide ja mälestusmärkide paleofauna analüüsimisel, millede luumaterjal on ladestunud suhteliselt lühema aja kestel, pole liiga killustatud ega paikne väga hajusalt.

Nimetus «isendite minimaalne arv» on tinglik. Antud näitaja ei haara mitte kindlalt minimaalset, vaid mitmesugustest asjaoludest olenevalt väga erineva osa tegelikust isendite arvust. Seetõttu oleks soovitav antud näitajat nimetada «isendite tingarvuks». On vaja uurida osteoloogilise materjali ladestumise tingimusi arheoloogiliste mälestusmärkide kultuurkihis ja täpsustada statistilisi ja graafilisi võtteid selle kvantitatiivsel läbitöötamisel. 


\title{
ZUR METHODIK DER BESTIMMUNG DER RELATIVEN BEDEUTUNG VON SÄUGETIERARTEN UND -GRUPPEN IM KNOCHENMATERIAL ARCHÄOLOGISCHER DENKMÄLER
}

\author{
K. Paaver
}

\section{Zusammenfassung}

Die bei archäologischen Ausgrabungen massenhaft zu Tage gefördeten Knochenüberreste von Tieren bilden ein wertvolles - wissenschaftliches Material, dessen Durcharbeitung Resultate sichert, die für die Paläozoologie, die Archäologie u. a. Disziplinen von wesentlicher Bedeutung sind. Zwecks einer weitgehenderen Verwertung der sich aus der Bearbeitung dieses Materials ergebenden Schlussfolgerungen ist unter anderem die weitere Entwicklung der Methodik der Sichtung und der statistischen Bearbeitung desselben wichtig. Der Verfasser stützt sich auf Daten und Erfahrungen, die bei der Bestimmung des Knochenmaterials archäologischer Denkmäler des ostbaltischen Gebiets erlangt worden sind; dabei behandelt er einige umstrittene Fragen der sog. "osteologischen Statistik», vornehmlich in Verbindung mit der Analyse der Paläofauna.

Kennziffern, die sich aus der quantitativen Durcharbeitung des osteologischen Materials ergeben, müssen kritisch bewertet werden. Bei der Charakterisierung der Paläofauna können sie nur unter allseitiger Berücksichtigung der tafonomischen Eigenart des gegebenen Knochenmaterials Verwendung finden.

Die Hauptaufgabe der quantitativen Analyse des osteologischen Materials besteht in der Feststellung des relativen Anteils verschiedener Tierarten und -gruppen im gegebenen Material. Dieser Anteil ergibt sich aufs genauste aus der tatsächlichen (absoluten) Zahl der Individuen, von denen die betreffenden Knochen und Knochenfragmente herrühren. Jedoch ist bei massenhaftem Auftreten von Material die Feststellung der tatsächlichen Individuenzahl aus verschiedenen Gründen praktisch unmöglich, und es werden statt dessen relative Kennziffern - «die Gesamtzahl der Knochenstücke» und die "Mindestzahl an Individuen» - verwendet. Die beiden letztgenannten Kennziffern geben aber den Anteil der Arten und Gruppen im Material nur ungenau an.

Die Fauna verschiedener Denkmäler und Schichten ist auf Grund der "Gesamtzahl der Knochenstücke» besser vergleichbar. Es ist zweckmässig, die «Mindestzahl an Individuen " als parallele Kennziffer zu benutzen, vor allem bei der Analyse der Paläofauna solcher Schichten und Denkmäler, wo die Ablagerung des Knochenmaterials verhältnismässig kurze Zeit gedauert hat, das Material nicht allzu zersplittert ist und nicht diffus liegt. Die ausschliessliche Verwendung der Kennziffer "Mindestzahl an Individuen" ist bei der Analyse massenhaften Materials nicht zweckmässig.

Die Bezeichnung «Mindestzahl an Individuen» ist bedingt. Die gegebene Kennziffer umfasst nicht den genau minimalen, sondern - je nach den verschiedenen Verhältnissen - einen sehr unterschiedlichen Teil der tatsächlichen Individuenzahl. Daher wäre es angebracht, diese Kennziffer «Bedingte Individuenzahl» zu nennen. Es ist vonnöten, die Bedingungen der Ablagerung des osteologischen Materials in der Kulturschicht der archäologischen Denkmäler zu untersuchen und die statistischen und graphischen Verfahren bei der quantitativen Bearbeitung desselben genauer $\mathrm{zu}$ bestimmen.

Institut für Zoologie und Botanik

der Akademie der Wissenschaften der Estnischen SSR
Eingegangen am 1. April 1958 